\title{
A propósito del Laudo del Servicio Vasco de Arbitraje Cooperativo n.o 7/2018, del 20 de julio de 2018. Doble contabilidad y asunción de pérdidas
}

On the Ruling of the Basque Service of Cooperative Arbitration num.

$$
\text { 7/2018 of } 20 \text { July } 2018 .
$$

Double accounting and take-over of losses

Rosa Otxoa-Errarte

Profesora Agregada de Derecho Mercantil UPV/EHU

* Correspondencia a/Corresponding author: Rosa Otxoa-Errarte. Universidad del País Vasco/Euskal Herriko Unibertsitatea (UPV/EHU) - rosa.ochoerrarte@ehu.eus

Cómo citar/How to cite: Otxoa-Errarte, Rosa (2019). "A propósito del Laudo del Servicio Vasco de Arbitraje Cooperativo n. ${ }^{7}$ 7/2018, del 20 de julio de 2018. Doble contabilidad y asunción de pérdidas", Gizarte Ekonomiaren Euskal Aldizkaria/ Revista Vasca de Economía Social, 16, 169-185. (https://doi.org/10.1387/reves.21220).

Recibido: 25 junio, 2019; aceptado: 25 junio, 2019.

ISSN 1698-7446 - elSSN 2444-3107 / (c) 2019 UPV/EHU

(c) (P) Esta obra está bajo una licencia

Creative Commons Atribución 4.0 Internacional 


\section{Antecedentes}

El laudo trae causa de un conflicto planteado por un socio de una Cooperativa de trabajo asociado que solicita la baja voluntaria, tras un período de excedencia, y que exige el reembolso de sus aportaciones que le correspondía con arreglo a la Ley y a los Estatutos.

El socio había iniciado su relación con la cooperativa en 1988 en calidad de trabajador con un contrato temporal, para pasar a ser socio en 1992, con un aportación a capital de 2.800 .000 pesetas. En noviembre de 2010 solicitó una excedencia voluntaria que, tras varios anuncios de reincorporaciones, acabaría con una baja voluntaria en enero de 2015 .

Los socios de la Cooperativa disponían desde su incorporación de una cartilla, en la que la primera anotación era la aportación a capital, y donde se anotaban anualmente las cantidades que, en concepto de retorno cooperativo, se asignaban a cada socio y que iban engrosando esa aportación. En el momento en que solicitó su baja en 2015, la cartilla del socio demandante arrojaba a su favor un saldo de $29.231,27 €$. Es la cantidad que reclamó a la cooperativa a título de reembolso de aportaciones.

La Cooperativa en su contestación a la demanda discrepó de la cantidad adeudada, rebajándola hasta los $852,63 €$, que se le seguían adeudando si bien no había vencido el plazo estatutario para su pago. Según su representante, la cartilla aportada como prueba documental por el demandante era solo una parte del documento acreditativo de las aportaciones realizadas; documento que debía ser completado con un "complemento de cartilla» al que el demandante no hacía alusión. La existencia de dos cartilla o de una cartilla y un complemento respondía a la existencia de una doble contabilidad.

La Cooperativa cerró la contabilidad correspondiente al ejercicio económico del año 2000 con pérdidas en su cuenta de resultados. Pasaba por una situación financiera delicada y el gerente de la misma, ante el temor de que la publicidad de esos resultados negativos agravara su situación dificultando aún más el acceso al crédito, planteó la opción de ocultar las pérdidas. Se consideró la idea de declarar unos resultados positivos mínimos y depositar en el Registro unas cuentas ficticias, por un lado, y seguir llevando una contabilidad legal, que incluso se sometería a auditoría externa y sería aprobada por la Asamblea, por otro. Con ello se buscaba salvaguardar la actividad de la Cooperativa y los puestos de trabajo de sus socios.

El Consejo Rector, del que formaba parte el socio demandante, decidió aceptar el planteamiento del gerente $\mathrm{y}$, aun siendo consciente de la irregularidad legal que suponía, llevarlo a la Asamblea para su aprobación. Ésta asumió la llevanza de la doble contabilidad por unanimidad, y decidió 
también que las pérdidas reales se imputarían a todos los socios, en el importe que correspondiera, en un "complemento de cartilla» o "cartilla extraoficial», que reflejaría el saldo real de la cartilla de cada socio. Al mismo tiempo la contabilidad ficticia se seguiría recogiendo en las cartillas iniciales, que desde ese momento reflejarían los resultados ficticios depositados en el Registro de Cooperativas de Euskadi.

Las pérdidas y la llevanza de doble contabilidad se prorrogaron hasta el año 2011, en el que el cambio de gerencia supuso el abandono de la práctica.

Año tras año la Asamblea aprobaba la imputación de pérdidas a los socios que se recogía en la denominada cartilla $\mathrm{B}$, tras haber aprobado la gestión y las cuentas anuales del ejercicio correspondiente, que habían sido previamente auditadas. Se acordaba también el depósito de las «cuentas oficiales» en el Registro. En la cartilla A, se fueron anotando pequeñas cantidades como «resultado del ejercicio». Es esa cartilla A la que el socio demandante presentó, junto con el escrito de demanda, al árbitro del procedimiento. Pretendía justificar así su crédito frente a la Cooperativa por un valor de 29.231, $27 €$, en concepto de reembolso de aportaciones. Su cartilla B, aportada por la Cooperativa, recogía el saldo de $852,63 €$.

Los peores ańos fueron el 2007, 2008 y 2010. De la prueba practicada resulta que en la Asamblea de 2008, que aprueba las cuentas de 2007 con un resultado negativo de $-742.144 €$, se decide «aplicar contra las cartillas de los socios» un importe de $-235.072 €$. La imputación se aprueba por unanimidad. Otros $-235.072 €$ se imputan al fondo de reserva obligatorio $\mathrm{y}$ al fondo para pérdidas a compensar en ejercicios futuros. Y los restantes $-181.614 €$ a partidas positivas a regularizar del balance. En la siguiente Asamblea en 2009, a preguntas de uno de los socios, se dijo que «el beneficio presentado en la contabilidad oficial fue mínimo». La cartilla A presentada por el demandante recoge un haber de 191,30 € ese ańo. La imputación de pérdidas en la "cartilla complementaria» es de $-1.043,63 €$.

En la Asamblea ordinaria de 2009 que aprobó las cuentas de 2008, ante la pregunta de uno de los socios, se respondió que «se presentaría en la contabilidad oficial un beneficio de aproximadamente $16.000 €$, y que esto se hacía por los bancos, "para que no nos cierren las puertas». Pero el resultado real fueron unas pérdidas de $-775.015 €$. Se aprobó la imputación «contra las cartillas de los socios en función de sus índices» de $290.766 €$, al fondo de reservas para compensar con resultados futuros $302.635 € \mathrm{y}$ a partidas positivas a regularizar del balance $181.614 €$. Esta aprobación se hizo también por unanimidad. La cartilla A del demandante recoge para ese ejercicio un haber de 209,86 €. La imputación de pérdidas en la "cartilla complementaria» $\mathrm{B}$ es de $-5.079,82 €$. 
El resultado del ejercicio de 2010 es de pérdidas por valor de $-1.107 .153,77 €$. Por unanimidad se decide en la Asamblea celebrada el 30 de abril de 2011 imputar $-276.788,44 €$ al fondo de reserva obligatorio y el resto $(-830.365,33 €)$ a las cartillas de los socios. La cartilla A del demandante recoge esta vez un debe de $-4.228,31 €$. Y la complementaria recoge una imputación de $-9.352,63 €$.

Según declararon todos los testigos, el reembolso de aportaciones a los socios salientes se hizo, en todo caso, teniendo en cuenta la cartilla $B$, que recogía las pérdidas que en las sucesivas Asambleas se habían imputado directamente a los socios.

El socio demandante fue miembro del Consejo Rector de la Cooperativa desde el 27 de junio de 1998 hasta el 1 de julio de 2002, según se desprendía de la documentación aportada con la contestación a la demanda. Y asistió a las Asambleas en que se acordó, por unanimidad, la imputación de pérdidas a las aportaciones de los socios al capital social.

Sin embargo, en su declaración negó tener conocimiento de la existencia de una doble contabilidad y de un "complemento de cartilla» o "cartilla B», que reflejara esas imputaciones de pérdidas a sus aportaciones al capital de la cooperativa. Preguntado por su participación en el Consejo Rector afirmó que fue elegido "para justificar que había gente del taller», pero que no entendía las decisiones que se tomaban. Y preguntado por las pérdidas aprobadas en Asamblea dijo que "no le suena que haya habido pérdidas» y que no se preocupaba de las cuentas porque «iba una parte positiva en la cartilla».

La magnitud de las pérdidas mencionadas anteriormente permitían, según indica el árbitro en su auto, dudar razonablemente de las aseveraciones del demandante, que, en cualquier caso, habría actuado con una negligencia inexcusable.

\section{Doctrina}

El árbitro no considera atendible la pretensión del socio demandante por las siguientes razones:

a) Unas cuentas falsas, por mucho que hayan sido depositadas en el Registro, seguirán siendo falsas, y no es posible para el socio sustentar sobre ellas ninguna pretensión económica.

b) El socio, miembro además del Consejo Rector de la Cooperativa, no puede pretender desconocer los acuerdos tomados por los órganos sociales en los que participa activamente,

c) La doctrina de los actos propios impide al socio, que ha votado en asamblea la imputación de pérdidas a los socios, pretender que tales 
pérdidas no existen, aunque esas pérdidas no aparezcan en la contabilidad depositada en el Registro de Cooperativas,

d) La imputación de pérdidas tiene carácter reglado y el socio tiene mecanismos para defenderse frente a la que considere improcedente, si no la impugna en el momento debido decaerá su derecho.

\section{Comentario}

\section{Doble contabilidad}

La llevanza de la contabilidad de los negocios, que surgió desde el interés de quienes desarrollaban actividades económicas de conocer la marcha de las operaciones acometidas y el rendimiento obtenido, para poder así organizar y planificar las mismas, es hoy en día una obligación regulada con normas jurídicas de carácter necesario. La contabilidad cumple dos funciones, una interna o técnica que responde a esa necesidad de conocer y controlar la propia actividad, y otra externa, pensada en los intereses de terceros que se relacionan con su titular. La marcha de la empresa, que se conoce a través de la contabilidad, interesa a sus acreedores, a posibles inversores, a socios minoritarios, en su caso, e interesa también al Estado por razones fiscales, y otras como la eventual concesión de ayudas públicas.

Ese interés de terceros es especialmente relevante cuando la situación económica y patrimonial del negocio atraviesa dificultades. Es cierto que el conocimiento de esas posibles dificultades puede funcionar para los terceros como un sistema de alerta de cara a la contratación futura. Y eso mismo puede empeorar las expectativas de recuperación. Pero la salvaguarda de los intereses de quienes se relacionan con el empresario, persona física o sociedad, exigen que la información ofrecida sea veraz, fiable.

La contabilidad no es solo un método para la medición de los resultados económicos de una empresa, sino un completo sistema de información que refleja la realidad económica de la misma. La contabilidad no crea una realidad patrimonial, sino que informa sobre ella y el derecho atribuye a esa información importantes consecuencias jurídicas que afectan a los intereses de terceros ${ }^{1}$. Por ello, ha de elaborarse de acuerdo a unas normas que, según establece el art. 34.2 del Código de Comercio, permitan «mostrar la imagen fiel del patrimonio, de la situación financiera y de los resultados de la empresa».

1 Vid., ROJO, A., en URÍA / MENÉNDEZ, Curso de Derecho Mercantil I, 2006, p. 168. 
Estas mismas normas se aplican a las cooperativas vascas, según establece el art. 71 de la Ley de Cooperativas del País Vasco vigente.

Lógicamente es esa contabilidad, que refleja la imagen fiel de la situación patrimonial y financiera de la sociedad, la que debe hacerse pública a través de su depósito en el Registro que corresponda, Mercantil o de Cooperativas.

A pesar de ello, la legislación mercantil no establece sanciones directas por el incumplimiento de la normativa sobre contabilidad, recogida en el propio Código de Comercio y en la legislación mercantil complementaria ${ }^{2}$. Ese incumplimiento sí tiene consecuencias, y muy serias, en caso de apertura de un procedimiento concursal. Así, de acuerdo con el artículo 164.2.1. ${ }^{\circ}$ de la Ley Concursal, el concurso se calificará como culpable en todo caso cuando el obligado a la llevanza de la contabilidad hubiera incumplido sustancialmente esa obligación, llevara doble contabilidad o hubiera cometido irregularidad relevante en la que llevara. Esa calificación tiene importantes consecuencias personales y patrimoniales para las personas afectadas y para sus cómplices, según el artículo 172.2 de la misma Ley. La primera de ellas es la de la inhabilitación para la administración de bienes ajenos durante un periodo de dos a quince ańos, para representar a cualquier persona durante el mismo período, y para el ejercicio del comercio (art. 13.2 del Código de Comercio). La segunda es la pérdida de cualquier derecho que las personas afectadas por la calificación del concurso o los declarados cómplices tuvieran como acreedores del concurso, así como la devolución de los bienes o derechos que hubieran obtenido indebidamente y la indemnización de los daños y perjuicios causados (art. 172.2.3. ${ }^{\circ} \mathrm{LC}$ ). Además, la sentencia de calificación del concurso como culpable puede condenar a los administradores y liquidadores a la cobertura total o parcial del déficit, en la medida en que la conducta que ha determinado la calificación culpable haya generado o agravado la insolvencia (art. 172 bis LC).

Pero el incumplimiento en materia de contabilidad también puede acarrear consecuencias penales. El art. 310 del Código Penal tipifica el «delito contable». La llevanza de contabilidades distintas que, referidas a una misma actividad y ejercicio económico, oculten o simulen la verdadera situación de la empresa lleva aparejada la pena de prisión de cinco a siete meses. La práctica de anotaciones contables ficticias en los libros o la no anotación de operaciones o transacciones económicas que oculten o simulen la verdadera situación de la empresa, lleva aparejada la misma pena, siempre que se hayan omitido las declaraciones tributarias o que las presen-

2 Más allá del cierre del Registro por falta de depósito que se establece en el art. 279.1 de la Ley de Sociedades de Capital. 
tadas fueren reflejo de su falsa contabilidad y que la cuantía, en más o menos, de los cargos o abonos omitidos y falseados exceda, sin compensación aritmética entre ellos, de $240.000 €$ por ejercicio económico.

Por otra parte, el art. 290 del mismo código establece que los administradores de una sociedad que falsearen las cuentas anuales u otros documentos que deban reflejar la situación jurídica o económica en la entidad, de forma idónea para causar perjuicio económico a la misma, a alguno de sus socios, o a un tercero, serán castigados con la pena de prisión de uno a tres ańos y multa de seis a doce meses. Penas que se imponen en su mitad superior si se llega a causar el perjuicio económico.

La Ley orgánica 1/2015 de 30 de marzo, añadió al Código Penal un capítulo VII bis al Título XIII del Libro II («De las insolvencias punibles»), cuyo art. 259.1 castiga con una pena de prisión de uno a cuatro años y multa de ocho a veinticuatro meses a quien, encontrándose en una situación de insolvencia actual o inminente, realice alguna de las siguientes conductas: 8 . Formule las cuentas anuales o los libros contables de un modo contrario a la normativa reguladora de la contabilidad mercantil, de forma que se dificulte o imposibilite el examen o valoración de la situación económica real del deudor, o incumpla el deber de formular el balance o el inventario dentro de plazo.

Los administradores, además, están sujetos a la responsabilidad derivada de los daños a terceros que el incumplimiento de la ley pueda ocasionarles, de acuerdo al régimen general de responsabilidad recogido para las sociedades de capital en los artículos 236 y siguientes de la ley de Sociedades de Capital y para las cooperativas vascas en los artículos 47 y 48 de la Ley de Cooperativas.

Y a partir de 2010, también las personas jurídicas son penalmente responsables por los delitos cometidos por sus representantes. Es decir, también las sociedades pueden sufrir las consecuencias de la llevanza de la doble contabilidad. Y ello con un resultado ciertamente gravoso, por ejemplo, a tenor de lo dispuesto en el art. 310 bis del Código Penal que establece como penas aplicables a las personas jurídicas las siguientes:

a) Multas.

b) Pérdida de la posibilidad de obtener subvenciones y ayudas públicas, y para gozar de beneficios e incentivos fiscales o de la Seguridad Social, por un plazo de tres a seis años.

c) Prohibición para contratar con el sector público.

Y si los jueces así lo determinan (art. 66 bis):

1. Disolución de la persona jurídica. La disolución producirá la pérdida definitiva de su personalidad jurídica, así como la de su capa- 
cidad de actuar de cualquier modo en el tráfico jurídico, o llevar a cabo cualquier clase de actividad, aunque sea lícita.

2. Suspensión de sus actividades por un plazo que no podrá exceder de cinco años.

3. Clausura de sus locales y establecimientos por un plazo que no podrá exceder de cinco ańos.

4. Prohibición de realizar en el futuro las actividades en cuyo ejercicio se haya cometido, favorecido o encubierto el delito. Esta prohibición podrá ser temporal o definitiva. Si fuere temporal, el plazo no podrá exceder de quince años.

5. Intervención judicial para salvaguardar los derechos de los trabajadores o de los acreedores por el tiempo que se estime necesario, que no podrá exceder de cinco años.

El Consejo Rector de la Cooperativa demandada, según se desprende de los hechos relatados en el laudo, era consciente de la irregularidad de llevar esa doble contabilidad. Probablemente no en toda su dimensión. A pesar de ello aceptó la propuesta hecha por el gerente como única «tabla de salvación» para seguir teniendo acceso a la financiación bancaria, "para que los bancos no cortaran el grifo». Y buscó el apoyo de la Asamblea que también aceptó el incumplimiento de la ley. Apoyo que, en su caso, como indica el art. 47.3 de la Ley Vasca de Cooperativas, no hubiera exonerado al Consejo de la responsabilidad por los daños eventualmente irrogados a terceros en caso de que la continuación de la actividad hubiera supuesto el empeoramiento de su situación económica y el incumplimiento de sus obligaciones para con ellos ${ }^{3}$.

El Consejo Rector se arriesgó a todas las consecuencias derivadas de la llevanza de una doble contabilidad que se han mencionado más arriba. Se elaboraron una cuentas anuales (B) conformes con la legislación mercantil, que fueron auditadas y aprobadas por las sucesivas Asambleas celebradas desde el año 2001 al 2011. Pero paralelamente se elaboraron otras, la contabilidad A, ficticias que se depositaron en el Registro de Cooperativas, con las que se pretendía mantener en el mercado una imagen de situación saneada que no correspondía a la realidad. Se pretendía engañar a acreedores y potenciales acreedores (sobre todo entidades financieras) ante el temor de

3 Es cierto que la peculiaridad del Consejo Rector como órgano de administración en el que participan los propios cooperativistas, no profesionales de la gestión, supone que la diligencia que les es exigible deba estimarse con más o menos rigor en función del carácter retribuido o no del cargo (art. 47.1 de la Ley Vasca). Pero ello no les exime totalmente de esa responsabilidad. Vid. al respecto, TATO PLAZA, A., Tratado de Derecho de Cooperativas, Tomo I, 2013, pp. 454 y ss. 
que el conocimiento de su verdadera situación les disuadiera de contratar y ello supusiera el final del proyecto empresarial y sus puestos de trabajo. Puede decirse que tuvieron suerte de que el riesgo asumido con la continuación de la actividad en esa situación no llevara a la insolvencia, no se materializara el riesgo de impago a los acreedores y nadie exigiera ningún tipo de responsabilidad por el incumplimiento legal en el que conscientemente incurrieron. Y ello incumbe también al socio demandante, que, de manera bastante inexplicable, exigió a su marcha, en concepto de reembolso de aportaciones, una cantidad que se correspondía con la contabilidad ficticia y no con la real, que con su voto se aprobaba en las sucesivas Asambleas y que fue mermando su aportación a capital.

Ciertamente, cuando se habla de doble contabilidad se piensa más bien en la ocultación de beneficio para eludir el pago de impuestos, pero, como se dice en el laudo, tampoco es extraño que lo que se pretenda ocultar sean las pérdidas. La sentencia del Juzgado de lo Mercantil de Badajoz de 30 de mayo de 2014, mencionada en el laudo, es un ejemplo paradigmático en el que, al contrario de lo que sucede en la Cooperativa que nos ocupa, sí se materializó la insolvencia y el concurso fue calificado como culpable, imponiéndose las sanciones de inhabilitación, pérdida de cualquier derecho personal de los afectados como acreedores concursales o de la masa y condena al pago de los créditos concursales o contra la masa que los acreedores no cobraran en la fase de liquidación, a las que hemos hecho referencia.

De las dos funciones que la contabilidad cumple, la Cooperativa fue respetuosa con la primera, la interna o técnica. Todos los socios fueron conscientes en todo momento de cuál era la situación económica y financiera de la misma. Y actuaron en consecuencia, acordando en Asamblea la imputación de pérdidas a los socios, que fueron viendo recortada la aportación realizada.

No ocurrió lo mismo con la segunda de las funciones, la externa, que satisface la necesidad de información de los terceros. Se les ofreció una información falsa a través del Registro. Pero, como se indica en el laudo, sobre esas cuentas falsas no es posible sustentar la pretensión que plantea el demandado.

En primer lugar, porque la información contable no prueba nada por sí misma. La contabilidad constituye un medio probatorio más del que disponen los jueces ${ }^{4}$ o, en su caso, los árbitros. El artículo 31 del Código de Comercio establece que «el valor probatorio de los libros de los empresarios y demás documentos contables será apreciado por los Tribunales conforme a las reglas generales del Derecho».

${ }^{4}$ ROJO, A., op cit. p. 181. 
En segundo lugar, porque el Registro no «sana» los defectos que puedan tener las cuentas anuales, ni tiene efectos de publicidad material que permitan a terceros confiar en la apariencia generada. No lo hace el Registro Mercantil y tampoco el de Cooperativas. Como señala el laudo, «el depósito no va precedido de un control, de una calificación que permita otorgar a esas cuentas una presunción de veracidad. El registrador, en el momento del depósito, no puede entrar a valorar la validez y la fiabilidad de los documentos presentados. Así, según art. 92 del Reglamento de organización y funcionamiento del Registro de Cooperativas de Euskadi, la calificación versará exclusivamente sobre si las cuentas anuales están debidamente aprobadas por la Asamblea General Ordinaria, si el Secretario ha certificado que las cuentas están firmadas por quienes las formulan y si las personas identificadas por el Secretario como firmantes de las actas figuran inscritas en el Registro los documentos presentados son los exigidos por la ley, si están debidamente aprobados y si contienen las preceptiva firmas. Se trata, por tanto, de un control meramente formal, que no prejuzga el contenido y la corrección material de las cuentas depositadas.

Ambos argumentos se acentúan, si lo depositado son unas cuentas totalmente ficticias elaboradas con el único objetivo de mantener la imagen, falsa, de una situación económica saneada, cuando existe otras elaboradas conforme la normativa contable en vigor, auditadas y aprobadas en Asamblea. Ello, naturalmente, al margen de la responsabilidad que nazca para los administradores del incumplimiento de sus obligaciones.

Pero es que además, en este caso el socio no puede ser considerado como un tercero de buena fe digno de protección. De los hechos declarados probados en el laudo se desprende claramente que era conocedor de la situación de la Cooperativa. Fue miembro del Consejo Rector cuando se dio inicio a la práctica de la doble contabilidad y estuvo presente en las Asambleas en las que se aprobaron las cuentas que recogían la verdadera situación económica de la Cooperativa y se acordó la imputación de pérdidas a los socios.

\section{Obligación de los socios de participar en los órganos sociales}

La Ley de Cooperativas del País Vasco en su artículo 23 recoge los derechos de los socios de las cooperativas, entre ellos el de elegir y ser elegidos para los cargos de los órganos de la cooperativa, y el de formular propuestas y participar con voz y voto en la adopción de todos los acuerdos de la Asamblea General y de los demás órganos de los que formen parte. Pero además, art. 22 a, entre las obligaciones de los socios, recoge la de «asistir a 
las reuniones de las Asambleas Generales y demás órganos a los que fuesen convocados".

No suele ser así en las normas sobre sociedades de capital, sí es habitual en las leyes de cooperativas. Hay que tener en cuenta que la cooperativa es una sociedad de base mutualista, en la que los socios se unen de forma voluntaria para satisfacer sus necesidades mediante la realización de la actividad cooperativizada, administrando democráticamente su empresa y ostentando el derecho esencial a participar en la gestión de los asuntos sociales. El socio cooperativista tiene un mayor poder de participación que el que tiene el accionista de una sociedad anónima, pero, correlativamente, tiene también una mayor responsabilidad frente a la sociedad y a sus consocios 5 . Esto explica que la asistencia a las Asambleas y la participación en otros órganos constituya una obligación y no solo un derecho. Como se dice en el auto "no cabe entender que la obligación se cumple por el mero hecho de estar en las reuniones sin atender a lo que se dice, se debate y se acuerda». Es lo que argumenta el socio demandante: no entendió que se hablara de pérdidas, ni siquiera cuando superaban el millón de euros. Y no preguntó porque en su cartilla originaria se seguían sumando cantidades.

La ley de sociedades de capital, tras la reforma del gobierno corporativo aprobada en 2014, recoge expresamente que los administradores tienen al deber de exigir y el derecho de recabar de la sociedad la información adecuada y necesaria que les sirva para el cumplimiento de sus obligaciones (art. 225.3 LSC). Quizá no pueda exigirse a los socios de las cooperativas, ni cuando participan en el Consejo Rector, el mismo nivel de diligencia que a los administradores de las sociedades de capital, sobre todo cuando no se trata de gestores profesionales. De ahí que la Ley de Cooperativas diga (art. 47.1) que la diligencia exigible «deberá estimarse con más o menos rigor en función del carácter retribuido o no del cargo». Pero esa modulación del deber de diligencia no puede llegar a la absoluta irresponsabilidad. Y cuando no se entiende de qué se está hablando en el Consejo, es obligación del consejero preguntar. Es lo que haría cualquier ordenado empresario (art. 47.1 de la Ley de Cooperativas).

No es verosímil que, cuando se discuta sobre la conveniencia de llevar una doble contabilidad para ocultar las pérdidas generadas en el ejercicio, haya un socio consejero que no comprenda la magnitud de lo que se de-

5 Sobre el principio de gestión democrática, MORILLAS, M.J., Concepto y clases de cooperativas», en PEINADO, J.I. y VAZQUEZ, T., Tratado de Derecho de Cooperativas, Tomo I, 2013, para quien ese principio incluye consideraciones acerca de derechos y obligaciones. «Los socios gestionan, en última instancia la sociedad y lo hacen de forma democrática: pueden y deben participar en las discusiones y en la toma de decisiones». 
cide. La primera reacción debiera ser recabar información, preguntar. Si no se hace, se incurre en una negligencia inexcusable, como se mantiene en el laudo.

\section{Doctrina de los actos propios}

De los hechos declarados probados por el laudo se desprende que el socio demandante era miembro del Consejo Rector de la Cooperativa cuando ésta decidió ocultar sus pérdidas ante el temor de perder el acceso a la financiación bancaria del que dependía su continuidad. Y las actas de las Asambleas indican que también participó en la adopción de los acuerdos de imputación de pérdidas a los socios, que se adoptaron a lo largo de varios años a partir de 2001. Acuerdos que implicaban la reducción de su aportación a capital. La imputación se hacía "contra las cartillas de los socios», según declararon los testigos en la vista. La pretensión de que el reembolso de las aportaciones, que le corresponde tras su salida de la Cooperativa, no contemple esas imputaciones incurre en un claro venire contra factum proprium rechazado por la jurisprudencia.

El Tribunal Supremo aplica el principio que impide contradecir los propios actos siempre en una situación procesal. Lo que se impide es que quien litiga tenga en el seno de un proceso una actitud que contradiga una actitud suya anterior previa a ese proceso. En este caso el socio no podría accionar, invocar o alegar en contra de su actuación previa, entendiendo como invocar o alegar, aportar hechos y argumentos sobre los que descanse una petición procesal ${ }^{6}$.

Actúa contra sus propios actos quien, como en este caso, entabla una demanda que contradice su conducta anterior. No se acepta que quien litiga sostenga en el proceso una afirmación distinta de la que, con su comportamiento, mantuvo en sus relaciones previas a la disputa jurídica ${ }^{7}$.

Desde 1864 el Tribunal Supremo ha ido perfilando las bases, requisitos y contenido de una regla con una clara conexión con el principio de la buena fe y con la protección de la confianza. Así, en la sentencia de 30 de octubre de 1995 mencionada en el laudo, se dice que "constituye un límite del ejercicio de un derecho subjetivo o de una facultad, como consecuencia del principio de buena fe y, particularmente, de la exigencia de observar, dentro del tráfico jurídico, un comportamiento coherente, siempre que concurran los requisitos presupuestos que tal doctrina exige para su

6 Vid. DIAZ PICAZO, L., La doctrina de los actos propios. Un estudio critico sobre la jurisprudencia del Tribunal Supremo, 2014, p. 172.

7 Ibid., p. 173. 
aplicación, cuales son que los actos propios sean inequívocos y que entre la conducta anterior y la pretensión actual exista una incompatibilidad o una contradicción según el sentido que de buena fe hubiera de atribuirse a la conducta anterior».

Del estudio de esa jurisprudencia se deducen los presupuestos para la aplicación de la regla de que nadie puede ir contra sus propios actos. Serían cuatro $^{8}$ :

1. Que una persona haya observado, dentro de una determinada situación jurídica, una cierta conducta jurídicamente relevante y eficaz.

2. Que posteriormente esa misma persona intente ejercitar un derecho subjetivo o una facultad, creando una situación litigiosa y formulando dentro de ella una determinada pretensión.

3. Que entre la conducta anterior y la pretensión posterior exista una incompatibilidad o una contradicción, según el sentido que de buena fe hubiera de atribuirse a la conducta anterior.

4. ${ }^{\circ}$ Que en ambos momentos, conducta anterior y pretensión posterior, exista una perfecta identidad de sujetos.

Se habla de conducta cuando se está ante un acto o una serie de actos que resultan reveladores de un modo general de proceder o comportarse, cuando revelan una determinada toma de posición de la persona respecto de algunos intereses vitales?.

En el caso resuelto en el laudo esa conducta consiste en la aprobación por el demandante, en su calidad de miembro del Consejo Rector, de la práctica de la elaboración de una doble contabilidad. Y en la aprobación en sucesivas Asambleas de unas cuentas anuales que reflejaban pérdidas, así como en la adopción de acuerdos de imputación de parte de esas pérdidas a los socios, entre los que se encontraba el propio demandante.

La relevancia jurídica de la conducta implica que se haya realizado «dentro de una determinada situación jurídica y que con ella haya quedado afectada una esfera de intereses», esos actos que engloban la conducta deben tener alguna repercusión jurídica en dicha situación. Y eficacia, que no se trate de actos inválidos. Todos estos requisitos pueden predicarse de la imputación de las pérdidas a los socios acordada en las sucesivas Asambleas de la Cooperativa (se volverá sobre la imputación más adelante).

8 Ibid., p. 257.

9 Ibid., p. 258. JARAMILLO. C.I., recoge también como presupuesto en el ámbito contractual la existencia de un perjuicio real o potencial para uno de los contratantes como consecuencia de la vulneración de la confianza que había depositado en el mantenimiento de la conducta inicial del otro contratante. Vid. La doctrina de los actos propios. Significado y proyección de la regla venire contra factum proprium en el ámbito contractual, La Ley, 2014, p. 346 y ss. 
Esa conducta ha de ser anterior a la formulación de un pretensión por parte de quien actúa contra sus propios actos. "Venire contra factum» viene a ser un límite a una pretensión ${ }^{10}$. La pretensión en nuestro caso es la reclamación del reembolso de las aportaciones, eludiendo la asunción de pérdidas que había sido aprobada para todos los socios en Asamblea. Pretensión litigiosa que el socio demandante fundamenta en la existencia de una contabilidad, que resulta ser falsa, y en una cartilla de socio, que presenta sin el «complemento» que cada socio tiene de la misma, y que recoge la contabilidad aprobada en Asamblea, con la distribución del resultado correspondiente.

El tercer elemento es el de la contradicción entre la conducta anterior y la pretensión litigiosa, la incompatibilidad entre lo que se pide y la posición mantenida anteriormente sobre la realidad sobre la que se proyecta la petición. Esa contradicción debe ser «repelida por la conciencia social como incompatible con la buena fe» ${ }^{11}$. Haber participado activamente en el engaño, en la práctica de la llevanza de una doble contabilidad, y acudir a la falsa, a la que ha sido objeto de publicidad, para eludir la consecuencia de la realidad de la situación financiera de la sociedad, repele por incompatible con la buena fe.

Por último, la aplicación de la doctrina exige que haya una identidad entre quien protagoniza la conducta y quien plantea la pretensión. En este caso este requisito tampoco plantea ninguna dificultad, puesto que es el socio que exige la devolución de sus aportaciones, sin contemplar la asunción de pérdidas acordada, quien con su voto en Asamblea contribuyó a la imputación de dichas pérdidas a los socios.

La consecuencia de la aplicación de la doctrina es la inadmisibilidad de la pretensión contradictoria, ya que se trata de un acto que el ordenamiento no puede proteger. Y no puede hacerlo porque la necesidad de coherencia del comportamiento del demandante limita sus derechos subjetivos, que solo podría ejercitar si no fueran incompatibles con la confianza suscitada por su conducta anterior ${ }^{12}$. La doctrina actúa así como mecanismo de excepción en sentido sustantivo, confiere al sujeto pasivo de la pretensión la facultad de oponerse a la misma ${ }^{13}$.

Por tanto, la Cooperativa está facultada para oponerse, como ha hecho, a la pretensión de que le sea restituida al socio demandante la aportación

10 Vid., DIAZ-PICAZO, L. op.cit. p. 276.

11 Ibid., p. 285.

12 Ibid., p. 301. En el mismo sentido JARAMILLO, C.I., op. cit., p. 405 y ss.

13 Muy gráfica es en este sentido la cita recogida por JARAMILLO, C.I., op. cit. p. 408, en la que se describe la doctrina "antes que como una espada, como un escudo, siendo la función natural de la construcción servir de barrera o excepción frente a un reclamo contradictorio a una conducta anterior del sujeto voluble» 
íntegra realizada por él al capital social, sin tener en cuenta las pérdidas imputadas en las sucesivas Asambleas.

\section{Obligación de asumir la imputación de pérdidas en la cuantía acordada por la Asamblea}

Los socios de las sociedades cooperativas vascas, al igual que ocurre con las sociedades de capital, no responden ante los acreedores de las deudas sociales. La ley lo establece claramente en su art. 56, «su responsabilidad por dichas deudas estará limitada a las aportaciones al capital social que hubieran suscrito». Además «una vez fijado el importe de las aportaciones a reembolsar, los socios que causen baja, no tendrán responsabilidad alguna por las deudas que hubiese contraído la cooperativa con anterioridad a su baja». Y en su Exposición de Motivos señala que «la responsabilidad limitada de los socios no podrá ser excepcionada por los estatutos». Ha sido clara la voluntad del legislador de establecer ese régimen de irresponsabilidad de los socios cooperativistas ante los acreedores societarios ${ }^{14}$. El mismo planteamiento se mantiene en el proyecto de ley para una nueva ley de cooperativas aprobado por el Gobierno Vasco en diciembre de 2018 y pendiente de tramitación parlamentaria ${ }^{15}$.

Pero, a diferencia de lo que ocurre con las sociedades de capital, entre las obligaciones que la ley de cooperativas impone a los socios está la de la asumir la imputación de las pérdidas en la cuantía acordada por la Asamblea General (art. 22.g). Así, cuando la cooperativa cierra su ejercicio económico con un resultado negativo, una parte de las pérdidas sociales, o la cuantía íntegra, puede imputarse al patrimonio de los socios. En la ley vasca, además, esa imputación es ilimitada ${ }^{16}$.

${ }_{14}$ No ocurre así en otras leyes autonómicas, que sí permiten el establecimiento vía estatutaria de una responsabilidad ilimitada. Lo hacen la Ley valenciana (art. 4), la madrileña (art. 5), la navarra (art. 8), la catalana (art. 54) o la extremeña (art. 76).

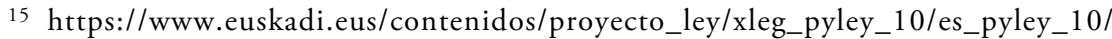
adjuntos/10.\%20Ley\%20de\%20Cooperativas\%20de\%20Euskadi/norma\%20castellano.pdf

16 Vid. al respecto, sobre la base de la Ley de Cooperativas de 1999, SUSO, J.M, «La imputación de pérdidas al socio en la liquidación concursal de la cooperativa», en Estudios sobre la Ley Concursal. Libro Homenaje a Manuel Olivencia. Tomo V, 2005, p. 4860 y ss. En el mismo sentido, PANIAGUA, M. «La determinación y la distribución de los resultados del ejercicio económico en la Sociedad Cooperativa: propuestas de armonización legislativa», RdS, n. ${ }^{\circ}$ 24, p. 204. A favor de una interpretación que limita la asunción de pérdidas a la cuantía aportada por el socio, GRIMALDOS, M.I., «El concurso de la cooperativa y su repercusión en el patrimonio personal de los socios", RDCP, n. ${ }^{\circ} 11,2009$, pp. 333 y ss. También VILLAFAÑEZ, I., Cooperativa y concurso. Estudio de las relaciones juridicas con sus socios, 2014, p. 261. 
Eso sí, tiene carácter reglado, ha de hacerse siguiendo el procedimiento legalmente establecido.

Así, según el art. 69.

1. Los Estatutos deberán fijar los criterios para la compensación de las pérdidas, siendo válido imputarlas a una cuenta especial para su amortización con cargo a futuros resultados positivos, dentro del plazo máximo de cinco años.

2. En la compensación de pérdidas la cooperativa habrá de sujetarse a las siguientes reglas:

a) A los fondos de reserva voluntarios, si existiesen, podrá imputarse la totalidad de las pérdidas.

b) Al Fondo de Reserva Obligatorio podrá imputarse como máximo el porcentaje medio de lo destinado a los fondos legalmente obligatorios en los últimos cinco ańos de excedentes positivos, o desde su constitución si ésta no fuera anterior a dichos cinco años.

c) La cuantía no compensada con los fondos obligatorios y voluntarios se imputará a los socios en proporción a las operaciones, servicios o actividades realizadas por cada uno de ellos con la cooperativa. Las pérdidas imputadas a cada socio se satisfarán de alguna de las formas siguientes:

1. Directamente o mediante deducciones en sus aportaciones al capital social o, en su caso, en cualquier inversión financiera del socio en la cooperativa que permita esta imputación, dentro del ejercicio siguiente a aquel en que se hubieran producido.

2. Con cargo a los retornos que puedan corresponder al socio en los cinco ańos siguientes. Si quedasen pérdidas sin compensar, éstas deberán ser satisfechas por el socio en el plazo máximo de un mes.

Es discutible que el art. 69.2 establezca o no una prelación a la hora de acordar la imputación de pérdidas a los socios. La utilización del término "podrá» apunta a que no es así17. Sin embargo, realiza la interpretación contraria el Juzgado de lo Mercantil de Donostia en las Sentencias 418/2012, de 10 de octubre o 190/2017, de 1 de septiembre, confirmada esta última por la Audiencia Provincial de Gipuzkoa $166 / 2018$, de 28 de marzo.

17 En este sentido VILLAFAÑEZ, ibid. p. 261. 
En el caso analizado en el laudo, en Asamblea General, se decidió sobre la forma en que se procedería a esa imputación, entre otras, mediante deducciones a los socios de sus aportaciones al capital social ${ }^{18}$ (art. 69.2.c.1 de la Ley de Cooperativas) o "contra cartilla», como se recoge en las actas. No hubo impugnaciones.

El Consejo Rector hizo el cálculo de la cantidad a reembolsar en tiempo pertinente (art. 8 del Reglamento de la Ley de Cooperativas de Euskadi) y ese cálculo le fue comunicado al socio saliente sin que, en el momento, manifestara disconformidad alguna. Debe estar, por ello, al cálculo comunicado.

El proyecto de Ley de Cooperativas de Euskadi sí modifica el régimen actual de la imputación de pérdidas a los socios en un aspecto importante: la imputación queda limitada por las aportaciones del socio (o por cualquier inversión financiera que permita tal imputación), de forma que si aún quedaran pérdidas sin compensar se realizará por la cooperativa una ampliación de capital debiendo el socio cuya aportación no alcance el nuevo mínimo de aportación obligatoria, causar baja si no efectúa nuevas aportaciones (art. 72). Pero en ningún caso afecta al patrimonio personal no vinculado con la cooperativa como aportación a capital o a otros activos que haya podido suscribir. Esto es, al patrimonio del socio no sujeto a «riesgo empresarial».

Todo ello, recuerda el art. 72, «con independencia de que la cooperativa deba instar el concurso conforme a la ley concursal». Habrá que ver cuál es la incidencia del régimen concursal en los plazos y trámites de imputación de pérdidas recogidos en la Ley.

18 Según FAJARDO, I.G., La gestión económica de la cooperativa: responsabilidad de los socios, 1997, pp. 71-72, lo correcto sería reducir el importe desembolsado de las aportaciones y no su número o valor. 